\title{
Cognitive, Behavioral and Emotional Empathy in Pharmacy Students: Targeting Programs for Curriculum Modification
}

\author{
Cassandra A. Tamayo ${ }^{1}$, Mireille N. Rizkalla ${ }^{1,2}$ and Kyle K. Henderson ${ }^{1,3 *}$ \\ 'Chicago College of Osteopathic Medicine, Midwestern University, Downers Grove, IL, USA, ${ }^{2}$ Department of Clinical \\ Integration, Chicago College of Osteopathic Medicine, Midwestern University, Downers Grove, IL, USA, ${ }^{3}$ Department of \\ Physiology and Department of Osteopathic Manipulative Medicine, Chicago College of Osteopathic Medicine, Midwestern \\ University, Downers Grove, IL, USA
}

\section{OPEN ACCESS}

Edited by:

Lon J. Van Winkle,

Midwestern University (retired), USA

Reviewed by:

Alejandro M. Mayer,

Midwestern University, USA

Deborah Virant-Young,

College of Osteopathic

Medicine-Michigan State University,

USA

*Correspondence: Kyle K. Henderson khende@midwestern.edu

Specialty section:

This article was submitted to Pharmaceutical Medicine and Outcomes Research,

a section of the journal

Frontiers in Pharmacology

Received: 20 January 2016

Accepted: 29 March 2016

Published: 19 April 2016

Citation:

Tamayo CA, Rizkalla MN and Henderson KK (2016) Cognitive,

Behavioral and Emotional Empathy

in Pharmacy Students: Targeting

Programs for Curriculum Modification.

Front. Pharmacol. 7:96.

doi: 10.3389/fphar.2016.00096
Introduction: Empathy is an essential trait for pharmacists and is recognized as a core competency that can be developed in the classroom. There is a growing body of data regarding levels of empathy in pharmacy students; however, these studies have not measured differences in behavioral, cognitive, and emotional empathy. The goal of this study was to parse the underlying components of empathy and correlate them to psychosocial attributes, with the overall goal of identifying curriculum modifications to enhance levels of empathy in pharmacy students.

Methods: IRB approval was obtained to measure empathy levels in pharmacy students attending Midwestern University. An online, anonymous survey administered through a secure website (REDCap) was used. This survey utilized the Jefferson Scale of Empathy (Medical Student version) and included questions regarding demographics and personality traits. Empathy questions were sub-divided into behavioral, cognitive, and emotional categories. Data are presented as mean \pm SEM with significance set at $P \leq 0.05$.

Results: Three hundred and four pharmacy students at Midwestern University participated in a fall survey with an overall response rate of $37 \%$. The average empathy score was $110.4 \pm 0.8$ on a scale of 20-140; which is comparable to empathy scores found by Fjortoft et al. (2011) and Van Winkle et al. (2012b). Validating prior research, females scored significantly higher than males in empathy as well as behavioral, cognitive, and emotional subcomponents. For the entire population, emotional empathy was significantly higher than cognitive and behavioral empathy $(P<0.05)$. Furthermore, negative correlations to empathy were observed for self-serving behavior $(R=0.490$, $P<0.001)$, medical authoritarianism $(R=0.428, P<0.001)$, and experience of coercion $(R=0.344, P<0.001)$. 
Conclusion: Overall, empathy levels in pharmacy students are similar to prior studies with females scoring higher than males. Emotional empathy may play a greater role than cognitive and behavioral empathy in this group of students. Targeted programs that promote volunteerism and activities that foster responsiveness to patient needs may attenuate self-serving behavior and medical authoritarianism and, therefore, improve empathy levels in pharmacy students.

Keywords: education, pharmacy, empathy, behavioral empathy, emotional empathy, cognitive empathy, interdisciplinary, Jefferson scale of medical student empathy

\section{INTRODUCTION}

Pharmacy is a human service profession with a unique position in providing health and functionality to patients. As with all humanistic professions, empathy is an essential trait for pharmacists and is recognized as a core competency that should be developed throughout graduate school. Consistent with this notion, the Accreditation Council for Pharmacy Education mandates that humanistic values and empathy be enriched and assessed as a core educational activity in graduate pharmacy education (Education, 2015).

Empathy is a multidimensional construct with behavioral, cognitive, and emotional domains (Larson and Yao, 2005). Cognitive empathy describes an individual's capacity to understand another person's perspective (Fjortoft et al., 2011; Shamay-Tsoory, 2011) as opposed to being self-oriented (Kohut, 1969; Basch, 1983; Eisenberg and Miller, 1987). Emotive empathy describes an affective characteristic, which involves experiencing and internalizing the feelings experienced by others (Eisenberg, 1989; Nunes et al., 2011). Behavioral empathy is action-oriented; it involves the outward expression of internally experienced (cognitive and emotive) processes which can be directed at improving clinical outcomes (Larson and Yao, 2005).

Prior research has sought to delineate the relative contribution between each of these empathy domains on clinical skills. One perspective is that cognitive empathy is the most predominant type of empathy in the medical setting (Halpern, 2003; Hojat, 2009); while others highlight the importance of both the behavioral and emotive aspects (Benbassat and Baumal, 2004; Manolakis et al., 2011). Yet it is also plausible that empathy, in its totality as a trinity, is the ideal vehicle that allows health care providers to practice patient-centered care, in which the patient's body, mind, and spirit can be evaluated comprehensively. Neuroscientists (Haas et al., 2015), empathy researchers (Hojat et al., 2009), and pharmacy educators (Maine and Vogt, 2009; Vogt and Finley, 2009; Education, 2015) continue to identify a significant need to examine empathy with greater scientific rigor.

The subcomponents of empathy originate at the neural level. Cognitive empathy is an executive function that recruits higherorder brain regions in the prefrontal and temporal cortices (Frith and Singer, 2008; Van Overwalle and Baetens, 2009) that enable "perspective taking," a process of materializing another's thoughts and intentions, known as the "Theory of Mind" (BaronCohen, 2009). In contrast, emotional empathy is a primitive function that recruits brain regions in the inferior frontal and parietal cortex (Shamay-Tsoory, 2011). This network, collectively known as the mirror neuron system, is instinctive and involved in emotional recognition (Shamay-Tsoory et al., 2009; ShamayTsoory, 2011). Behavioral empathy is a construct that is defined as actions taken in response to the internal experience of cognitive and/or emotional empathy. Although behavioral empathy may be triggered by both cognitive and emotional processes (ShamayTsoory, 2011), the exact trigger must be distinguished, as they lead to very different clinical behaviors (Nightingale et al., 1991). For example, a cognitively empathetic pharmacist would be more inclined to act upon the content and quality of patients' symptoms, whereas an emotionally empathetic pharmacist would be more inclined to sympathetically respond to patients' feelings of pain and suffering.

The current project grew out of a theoretical model that recognizes cognitive empathy as an adaptive function that can be taught. For example, by increasing 'perspective taking, a pharmacist is better equipped to predict motives and health/risk behaviors such as medication compliance and substance abuse (Darbishire et al., 2012). Therefore, cognitive empathy emphasizes the appropriateness of the biopsychosocial model to health care, wherein the full realization of health is achieved within the context of a complex interaction of biological, psychological, and social factors. Theoretical models have hypothesized a linear relationship between cognitive empathy and positive outcomes, meaning that the outcomes progressively improve as a function of an increase in cognitive empathy. In contrast, excessive emotional empathy can cloud the neutrality that is necessary in clinical practice, thus cultivating compassion fatigue, exhaustion, and vicarious traumatization (Linley and Joseph, 2007). The relationship between emotional empathy and clinical outcomes is characterized by a bell-shaped curve, meaning that emotional empathy can be beneficial to a limited extent, but then becomes detrimental in excess (Hojat et al., 2009).

Empathy levels in health related professions can be measured by: self-assessment (first person assessment), patient-rating (second person assessment), and observation (third person assessment) (Hemmerdinger et al., 2007). When large sample sizes are evaluated, self-assessment questionnaires are the most efficient and the Jefferson Scale of Physician Empathy (Hojat et al., 2001), and student empathy (Hojat et al., 2004) were developed for this purpose. Prior research has assessed empathy levels and tracked its temporal and individual psychosocial differences in medical (Mehrabian et al., 1988), paramedic (Nunes et al., 2011) and allied health professionals (Williams 
et al., 2014), and similar research on pharmacy students is rapidly growing (Vogt and Finley, 2009; Fjortoft et al., 2011; Manolakis et al., 2011; Nunes et al., 2011; Darbishire et al., 2012; Van Winkle et al., 2012a,b, 2013a; Wilson et al., 2012; Chen et al., 2015; Jeon and Cho, 2015; Kerr et al., 2015; Lor et al., 2015). However, very little is known about individual differences in emotional, cognitive, and behavioral empathy. Consequently, sufficient attention has not been directed toward the malleability and enhancement of the subcomponents of empathy in pharmacists-in-training. The goal of this study was to parse the components of empathy and correlate them to psychosocial attributes, thereby elucidating the composition of empathy in pharmacy students and advancing our understanding of what traits promote or erode empathy. A better conceptualization of empathy will not only provide an innovative framework for studying empathy in pharmacy students, but will also help to identify curriculum modifications to optimize empathy subcomponents.

\section{MATERIALS AND METHODS}

Midwestern University Institutional Review Board (IRB) approval was obtained to measure empathy levels in pharmacy students attending Midwestern University. A voluntary, online, anonymous survey was administered through a secure web-based application called REDCap (Research Electronic Data Capture) hosted at Midwestern University (Harris et al., 2009). This survey utilized the Jefferson Scale of Empathy (Medical Student version). These questions were then sub-divided into behavioral (action), cognitive (perspectivetaking), and emotional (expressed feeling), categories and the responses were tabulated (Appendix). Questions targeting personality traits utilized the same seven point Likert scale used by the Jefferson empathy survey. Data was organized with Microsoft Excel and statistical significance determined with Sigma Stat 12.5 software. For group comparisons, normality and variance were tested and appropriate Analysis of Variance (ANOVA or ANOVA on Ranks) and post hoc tests (Holm-Sidak or Tukey) were used to determine significance $(P \leq 0.05)$.

\section{RESULTS}

Three hundred and four pharmacy students at Midwestern University participated in the fall survey with an overall response rate of $37 \%$. The response rate for each class year (1st to 4 th) was: $31,29,74$, and $13 \%$, respectively. The average empathy score was $110.4 \pm 0.8$, on a scale of $20-140$ which is comparable to empathy scores found by Fjortoft et al. (2011) and Van Winkle et al. (2012b). To compare the effect of gender and class year on the Jefferson Empathy score, a 2-way ANOVA was used. Validating prior research, females scored significantly higher than males overall $(112.7 \pm 0.9$ vs. $106.1 \pm 1.5 ; P<0.001)$ and specifically in the 2 nd and 4 th year $P<0.05$ (Figure 1). Empathy scores did not change in male students between class year, but were

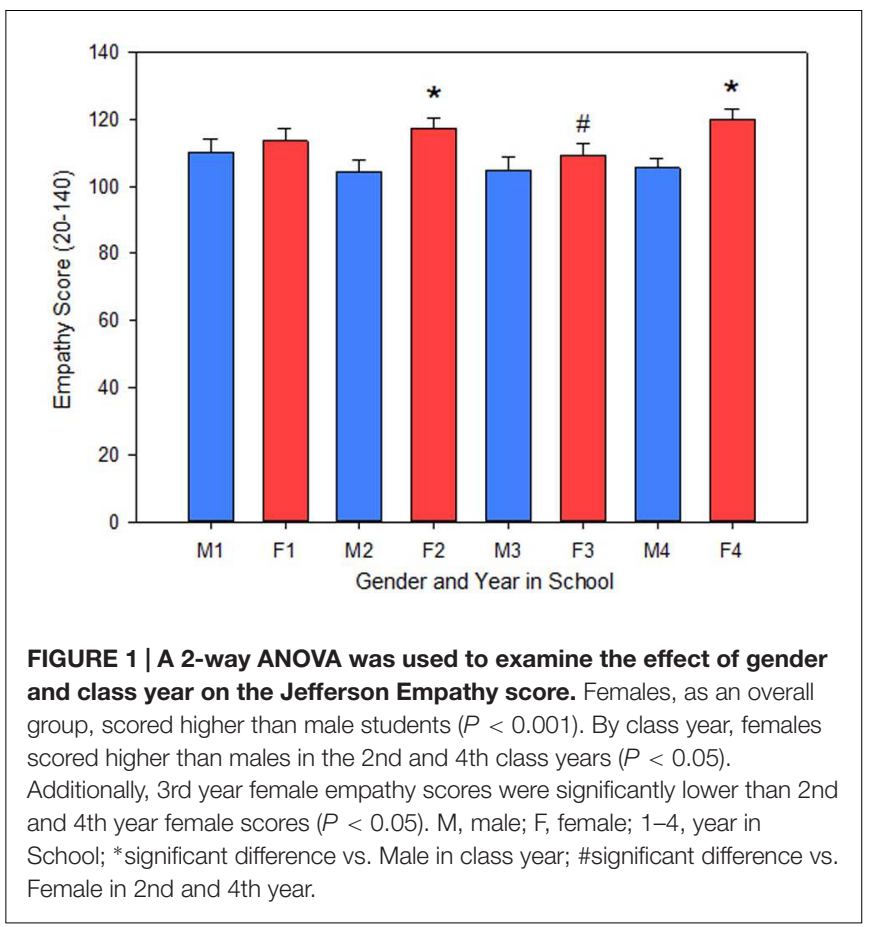

significantly lower in 3rd year female students vs. 2nd and 4th year female students $P<0.05$ (Figure 1). There was no effect of age $(P=0.67)$, ethnicity $(P=0.09)$, religion $(P=0.40)$, marital status $(P=0.17)$, birth order $(P=0.22)$, highest family education $(P=0.53)$, or debt $(P=0.68)$ on Jefferson empathy scores.

Empathy questions were sub-divided into emotional, cognitive, and behavioral categories and answers were scored and ranked on a scale of $0-100 \%$. To compare the effect of gender, year in pharmacy school, and empathy sub-components (behavioral, cognitive, and emotional), a 3-way ANOVA was used. As a graduate population, pharmacy students scored significantly higher in emotional empathy $78.1 \pm 0.8 \%$ vs. cognitive empathy $73.9 \pm 0.7 \%(P=0.005)$ as well as behavioral empathy $73.8 \pm 0.9 \%(P=0.011)$. The distribution of emotional, cognitive, and behavioral empathy scores and student numbers are presented in Figure 2. There was not a significant interaction between individual subcomponents of empathy and class year $(P=0.441)$ or gender $(P=0.441)$. However, subcomponent scores were significantly lower in the 3 rd year class $(P<0.05)$; Table 1. Similar to the Jefferson empathy scores, females scored significantly higher than males in the 2nd, 3rd, and 4th class years $(P<0.05)$; and 3rd year females scores were lower than 1st, 2 nd, and 4 th year female scores $(P<0.05)$; Table 1 . Additionally, female 4 th year empathy scores were greater than 1st year female scores $(P=0.02$; Table 1$)$. In male students, empathy scores were greater in 1 st year vs. 3 rd year $(P=0.024$; Table 1).

Questions targeting personality traits such as self-serving motive, coercion, medical authoritarianism, elitism, and egalitarianism were correlated to empathy scores. The selfserving statement, "I do not volunteer because it hinders (or 


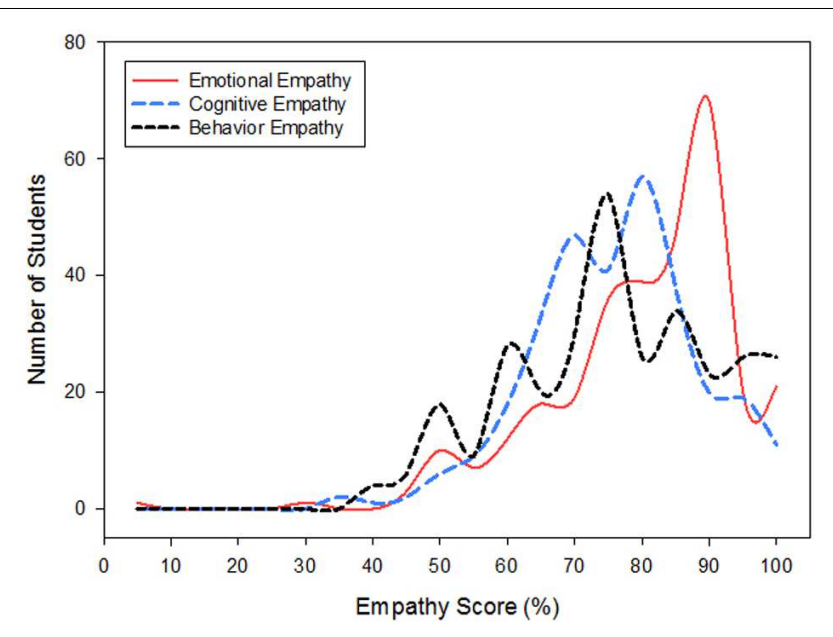

FIGURE 2 | Emotional empathy was greater than Cognitive $(P=0.005)$ and Behavioral empathy $(P=0.01)$ in Pharmacy students. Scores and population distributions are shown.

partially hinders) my ability to get ahead." was negatively correlated to empathy $(R=0.49, P<0.001)$ and the behavioral subcomponent of empathy $(R=0.371, P<0.001$; Figure 3 , Table 2). The experience of coercion to enter a health related profession was assessed with the statement "I feel pressured to enter the health professional field." Answers to this statement were negatively correlated to empathy $(R=0.344, P<0.001)$ and closely related to the emotional subcomponent of empathy $(R=0.334, P<0.001$, Table 2). Medical authoritarianism was assessed by responses to "Conscientious patients deserve better health care than those with self-inflicted conditions." and negatively correlated to empathy $(R=0.428, P<0.001)$. This question had a strong cognitive empathy component $(R=0.396$, $P<0.001$, Table 2). There was a negative association between empathy scores and elitism as assessed by the question "Those who contribute the most to society should get better health care" ( $R=0.426, P<0.001)$. On the other hand, egalitarianism, assessed by the question, "We should do what we can to equalize health care for different groups," was positively associated with empathy scores $(R=0.29, P<0.001)$ with strong associations to behavioral empathy $(R=0.265, P<0.001)$, cognitive empathy $(R=0.283, P<0.001)$, and emotional empathy $(R=0.212$, $P<0.001)$.
The categorization of the 20 Jefferson empathy questions into subcomponents of empathy were not equally distributed (Behavioral 20\%, Cognitive 45\%, and Emotional 35\%). Therefore, correlations to behavioral empathy had less power because fewer Jefferson empathy questions are related to behavior. Nonetheless, questions that targeted subcomponents of empathy were effective. Of three questions targeting behavior, cognition, or emotion; the $R$-value for behavioral empathy was greatest for the question targeting behavior (Table 2). The question targeting cognition had the highest $R$-value for cognitive empathy, and the question targeting emotion had the highest $R$-value for emotional empathy.

\section{DISCUSSION}

To the best of our knowledge, no psychometrically sound research instrument is available to measure empathy specifically among pharmacy students. Consistent with this, researchers continue to identify a significant need to develop instruments to measure empathy (Hojat et al., 2009). The Jefferson scale for empathy possesses strong psychometric properties (Hojat, 2007), including construct validity (Hojat et al., 2001, 2002b) criterion validity (Hojat et al., 2002a), test-retest reliability, and internal consistency (Hojat et al., 2001, 2002b). The Jefferson scale is also amenable to word adaptations to match the student audience, while still retaining such properties (Hojat et al., 2009). Accordingly, we adapted the Jefferson Scale of Physician Empathy to pharmacists-in-training and identified questions within the survey that target empathy subcomponents.

The present study assessed three subcomponents of empathy and how they relate to various personality and psychosocial traits in pharmacy students. Our study demonstrated that, as a graduate population, emotional empathy scored highest while overall empathy scores were lower in the 3rd year class. The observed decline in graduate health care student empathy supports prior research in nursing students (Wilson et al., 2012) as well as in medical students (Neumann et al., 2011); however, it contradicts previous data for pharmacy students (Wilson et al., 2012). One important implication of the differences observed between emotional and cognitive empathy relates to how amenable these characteristics are to change. Based on the neurological underpinning, it can be assumed that emotional empathy is less amenable to

TABLE 1 | Empathy subcomponent scores \%, gender, and class year are presented.

\begin{tabular}{|c|c|c|c|c|c|c|c|c|}
\hline & M1 & $\mathbf{F 1}$ & M2 & F2 & M3 & F3 & M4 & F4 \\
\hline Behavior (\%) & $75.2 \pm 2.5$ & $78.0 \pm 2.2$ & $65.2 \pm 4.4$ & $80.5 \pm 2.1$ & $67.1 \pm 2.0$ & $71.7 \pm 1.5$ & $72.1 \pm 3.0$ & $85.3 \pm 2.7$ \\
\hline Cognitive (\%) & $72.3 \pm 3.0$ & $75.4 \pm 1.9$ & $69.8 \pm 3.0$ & $79.2 \pm 1.3$ & $70.8 \pm 1.8$ & $73.3 \pm 1.2$ & $70.9 \pm 3.1$ & $78.9 \pm 2.6$ \\
\hline Emotional (\%) & $78.8 \pm 2.8$ & $81.0 \pm 1.8$ & $73.8 \pm 3.4$ & $83.9 \pm 1.3$ & $72.5 \pm 2.4$ & $76.9 \pm 1.4$ & $71.0 \pm 2.7$ & $87.6 \pm 1.8$ \\
\hline
\end{tabular}

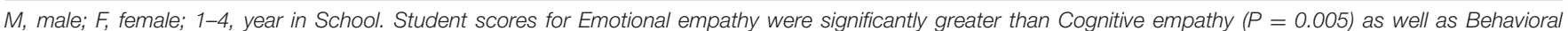

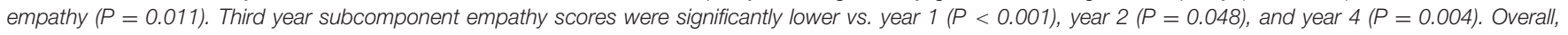

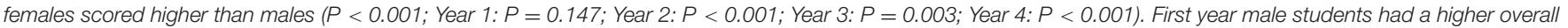

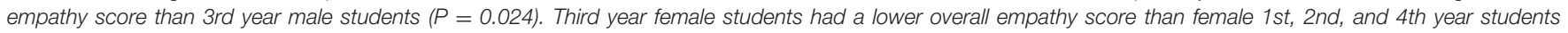
$(P<0.01)$. Additionally, female 4 th year scores were significantly higher than 1 st year female students $(P=0.023)$. 


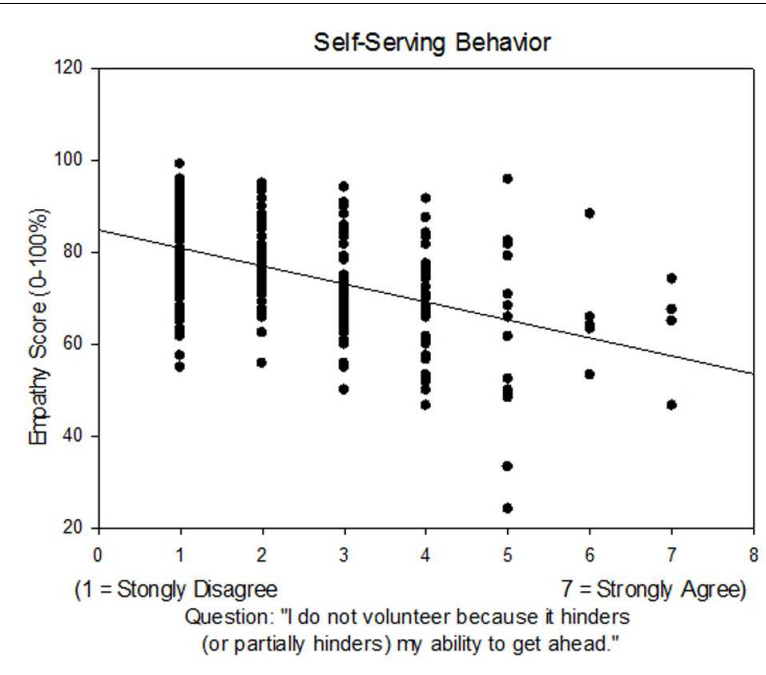

FIGURE 3 | Jefferson empathy scores were correlated to Likert scaled responses to the question, "I do not volunteer because it hinders (or partially hinders) my ability to get ahead." Linear regression: $R=0.490$, $P<0.001$.

change, as it is the most primitive and elicits automatic neural processes (de Waal, 2008; Rizzolatti et al., 2009). In contrast, cognitive empathy may be substantially enhanced by education, which is supported by a body of research on controlled neural processes and cortical-based plasticity. That is, as students gain academic experience and work with patients, they develop constructs that alter their empathetic system that may either increase or decrease their empathetic response. This neurological distinction leads most investigators to hypothesize that cognitive empathy can be augmented while emotional empathy is less likely to change with time and experience.

Our additional questions revealed three personal(ity) characteristics (coercion, self-serving behavior, and medical authoritarianism) that significantly correlated with empathy scores. These characteristics were selected for two reasons. First, each characteristic independently relates to different aspects of empathy: emotional, behavioral, and cognitive, respectively. Second, these characteristics are a product of life experience, and thus may still be responsive to education and intervention programs.
Students who felt coerced to enter a health professional field demonstrated lower emotional empathy. At the same time, there was a decline in emotional empathy in 3rd vs. 2nd year students. This contradicts the theory that emotional empathy is highly embedded in our neuronal construct and less likely to change. These results suggest emotional empathy levels could be changed in the academic setting. Secondly, the data indicate that coerced students may be less equipped for pharmacy because of its consequential association with lower emotional empathy. Potential mechanisms linking coercion to depressed emotional empathy levels may be increased stress, anxiety, and general unhappiness in their chosen career. Taken together, coercion may be a dispositional factor that moderates responsiveness to educational programs, meaning that students who were coerced into the field may learn from, and benefit differently, than those who were not coerced.

In the present study, self-serving behavior was negatively correlated with behavioral empathy, as suggested by responses to a question on volunteerism. By definition, individuals who are self-serving inherently have less comfort with, and preference against, extending themselves to outreach programs. Volunteering activities may be particularly stressful because they engage the student in a process that is contrary to their dispositional tendency. This dispositional discomfort may be compounded by the fact that volunteering competes with the students' studies for limited time, effort, and attention. Therefore, academic requirements that promote volunteering as a method to enhance empathy levels may cause more anxiety in students with a low reservoir of behavioral empathy.

Students who endorsed statements of medical authoritarianism scored lower on cognitive empathy. Recent studies have confirmed that elitist attitudes predict lower empathy and patient-centeredness ${ }^{32,33}$. Doctoral training explains the complex pathophysiology of and risk behaviors causing disease. Thus, treatment is simplified to pharmaceutical and behavioral modification. However, patient compliance is often substantially hindered by a myriad of psychological, social and educational barriers. Without a solid appreciation for this multilayered etiology, it becomes increasingly difficult to cognitively empathize with patients. Furthermore, studies demonstrate that medical authoritarianism increases over the course of graduate training, while empathy decays (Tsimtsiou et al., 2007). This pattern of heightened medical authoritarianism and decaying empathy may be changed by encouraging circular

TABLE 2 | The Jefferson empathy score and subcomponents of empathy (behavioral, cognitive, and emotional) were correlated to responses from questions that targeted self-serving motivation, medical authoritarianism, and coercion.

\begin{tabular}{|c|c|c|c|}
\hline & Self-serving motive (behavioral) & Medical authoritarianism (cognitive) & Coercion (emotional) \\
\hline Jefferson: empathy & $R=0.490 ; P<0.001$ & $R=0.428 ; P<0.001$ & $R=0.344 ; P<0.001$ \\
\hline Behavioral empathy & $R=0.371 ; P<0.001$ & $R=0.335 ; P<0.001$ & $R=0.211 ; P<0.001$ \\
\hline Cognitive empathy & $R=0.442 ; P<0.001$ & $R=0.396 ; P<0.001$ & $R=0.321 ; P<0.001$ \\
\hline Emotional empathy & $R=0.447 ; P<0.001$ & $R=0.373 ; P<0.001$ & $R=0.334 ; P<0.001$ \\
\hline
\end{tabular}

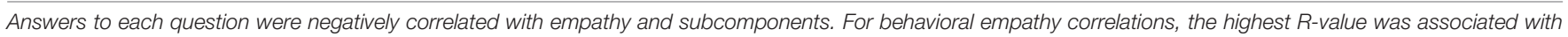

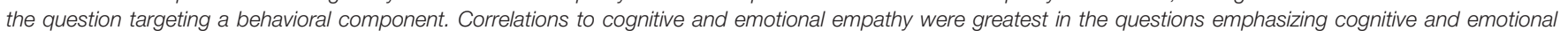
aspects, respectively. 
activities that offset other experiential factors that contribute to the decline in empathy during graduate training (Van Winkle et al., 2013b).

\section{Educational Implications}

Educational reform that prevents the decline in empathy and embraces measureable outcomes should be considered a mandate in pharmacy training. In an effort to advance this mission, we set out to identify the relationship between individual traits and the subcomponents of empathy. In identifying these relationships, we are better positioned to target specific characteristics that either enhance or impinge upon students' development and maintenance of empathy.

The present study demonstrated that emotional empathy was greater than cognitive or behavioral empathy. Given the relationship between excessive emotional empathy and negative clinical outcomes, it may be important for educational programs to intervene to moderate this trait, while concurrently working to enhance cognitive empathy. Whilst workshops lay the foundation and keep empathy afloat in primary years (Van Winkle et al., 2009, 2012b), a cynical transformation appears to creep in during latter years. This escalation of cynicism has long been recognized in neighboring healthcare professions (Becker, 1961; Wolf et al., 1989) and has been described as "traumatic deidealization" (Kay, 1990) and "dehumanization." (Hojat et al., 2005). Explanatory models for this decline, may be: the development of biases against some patient populations, frustration with the health care system, or simply exhaustion from academic workload. As an extension of Midwestern University's previous initiative, buffer programs in the 3rd year may refresh students' cognitive empathetic abilities. Finally, a concerted effort to facilitate volunteerism and foster responsiveness to patient needs, may prevent declines in behavioral empathy (Van Winkle et al., 2013b).

\section{Implications for Inter-Professional Healthcare Collaborations}

A prominent feature of effective healthcare providers is interdisciplinary collaboration. Collaborative models are demonstrated when traditional disciplinary boundaries are crossed through a pooling of information. Inter-professional collaboration has seen growing support in the empirical literature for its use in addressing multi-faceted problems and for enhancing therapeutic outcomes.

There are successful examples of interdisciplinary learning that result in improved collaborative scores. For example, Van Winkle et al. (2012a, 2013a) have promoted inter-disciplinary educational programs to enhance cognitive empathy and to improve collaborative scores between pharmacy and medical students. Apart from demonstrating the interdependency of cognitive empathy and collaborative attitudes, their findings also demonstrate that pharmacy students have significantly greater physician-pharmacist collaborative tendencies. In this regard, pharmacy students could favorably influence medical students toward collaboration in critical thinking/reflection exercises (Van Winkle et al., 2013a).
The academic setting is an ideal environment to foster empathy levels in graduate students pursuing health related professions. Early implementation in preclinical years may be the most effective implementation strategy, as these students are a captive audience wherein mandatory group workshops could be controlled and optimally delivered.

\section{Study Limitations}

This exploratory survey does not have longitudinal data. Therefore, changes in class year may be due to a unique class population and/or the time course of pharmaceutical graduate education. Survey data are unique to Midwestern University and may not be reflective of all pharmacy students. Future, longitudinal studies will provide repeated measures and greater population numbers adding to the confidence of future results and validation of their educational implications.

\section{CONCLUSION}

This exploratory survey of empathy in pharmacy students validates prior literature demonstrating that empathy levels are higher in females and frequently decline during the 3rd year of graduate training. Our data suggest that emotional empathy may play a greater role than cognitive and behavioral empathy in this group of students, and may be amenable to change. Academic programs could be implemented to promote volunteerism, and activities that foster awareness and responsiveness to patient needs; thereby augmenting cognitive and behavioral empathy levels and preparing students to be more effective pharmacists.

\section{AUTHOR CONTRIBUTIONS}

$\mathrm{KH}, \mathrm{MR}$, and $\mathrm{CT}$ were present at the inception of the research idea, contributed to the literature review, the IRB application and approval process, assisted in data collection and interpretation, writing of the manuscript and editing, and can defend the research in public.

\section{FUNDING}

Funding for this research was provided by the Chicago College of Osteopathic Medicine at Midwestern University.

\section{ACKNOWLEDGMENTS}

The authors wish to acknowledge Disha Ankola for her assistance in helping with the literature review and Elizabeth Tallman for her assistance with the REDCap survey.

\section{SUPPLEMENTARY MATERIAL}

The Supplementary Material for this article can be found online at: http://journal.frontiersin.org/article/10.3389/fphar.2016. 00096 


\section{REFERENCES}

Baron-Cohen, S. (2009). Autism: the empathizing-systemizing (E-S) theory. Ann. N. Y. Acad. Sci. 1156, 68-80. doi: 10.1111/j.1749-6632.2009.04467.x

Basch, M. F. (1983). Empathic understanding: a review of the concept and some theoretical considerations. J. Am. Psychoanal. Assoc. 31, 101-126. doi: $10.1177 / 000306518303100104$

Becker, E. (1961). "Private" versus "public" logic: some anthropological and philosophical reflections on the problem of mental "health". Am. J. Psychiatry 118, 205-211. doi: 10.1176/ajp.118.3.205

Benbassat, J., and Baumal, R. (2004). What is empathy, and how can it be promoted during clinical clerkships? Acad. Med. 79, 832-839. doi: 10.1097/00001888200409000-00004

Chen, A. M., Kiersma, M. E., Yehle, K. S., and Plake, K. S. (2015). Impact of an Aging Simulation Game on Pharmacy Students' Empathy for Older Adults. Am. J. Pharm. Educ. 79:65. doi: 10.5688/ajpe79565

Darbishire, P. L., Plake, K. S., Kiersma, M. E., and White, J. K. (2012). An introductory pharmacy practice experience on improving medication adherence. Am. J. Pharm. Educ. 76:42. doi: 10.5688/ajpe 76342

de Waal, F. B. M. (2008). Putting the altruism back into altruism: the evolution of empathy. Annu. Rev. Psychol. 59, 279-300. doi: 10.1146/annurev.psych.59.103006.093625

Education, A. C. F. P. (2015). Accreditation Standards and Key Elements for the Professional Program in Pharmacy Leading to the Doctor of Pharmacy Degree. Available at: https://www.acpe-accredit.org/pdf/Standards2016FINAL.pdf

Eisenberg, N. (1989). Empathy and related vicarious emotional responses. New Dir. Child Dev. 44, 1-7. doi: 10.1002/cd.23219894402

Eisenberg, N., and Miller, P. A. (1987). The relation of empathy to prosocial and related behaviors. Psychol. Bull. 101, 91-119. doi: 10.1037/0033-2909. 101.1.91

Fjortoft, N., Van Winkle, L. J., and Hojat, M. (2011). Measuring empathy in pharmacy students. Am. J. Pharm. Educ. 75:109. doi: 10.5688/ajpe 756109

Frith, C. D., and Singer, T. (2008). The role of social cognition in decision making. Philos. Trans. R. Soc. Lond. B Biol. Sci. 363, 3875-3886. doi: 10.1098/rstb.2008.0156

Haas, B. W., Brook, M., Remillard, L., Ishak, A., Anderson, I. W., and Filkowski, M. M. (2015). I know how you feel: the warm-altruistic personality profile and the empathic brain. PLOS ONE 10:e0120639. doi: 10.1371/journal.pone. 0120639

Halpern, J. (2003). What is clinical empathy? J. Gen. Intern. Med. 18, 670-674. doi: 10.1046/j.1525-1497.2003.21017.x

Harris, P. A., Taylor, R., Thielke, R., Payne, J., Gonzalez, N., and Conde, J. G. (2009). Research electronic data capture (REDCap)-a metadata-driven methodology and workflow process for providing translational research informatics support. J. Biomed. Inform. 42, 377-381. doi: 10.1016/j.jbi.2008.08.010

Hemmerdinger, J. M., Stoddart, S. D., and Lilford, R. J. (2007). A systematic review of tests of empathy in medicine. BMC Med. Educ. 7:24. doi: 10.1186/1472-69207-24

Hojat, M. (2007). Empathy in patient care: antecedents, development, measurement, and outcomes. Choice 44, 1565-1565.

Hojat, M. (2009). Ten approaches for enhancing empathy in health and human services cultures. J. Health Hum. Serv. Adm. 31, 412-450.

Hojat, M., Gonnella, J. S., Mangione, S., Nasca, T. J., Veloski, J. J., Erdmann, J. B., et al. (2002a). Empathy in medical students as related to academic performance, clinical competence and gender. Med. Educ. 36, 522-527. doi: 10.1046/j.1365-2923.2002.01234.x

Hojat, M., Gonnella, J. S., Nasca, T. J., Mangione, S., Vergare, M., and Magee, M. (2002b). Physician empathy: definition, components, measurement, and relationship to gender and specialty. Am. J. Psychiatry 159, 1563-1569. doi: 10.1176/appi.ajp.159.9.1563

Hojat, M., Mangione, S., Nasca, T. J., Cohen, M. J. M., Gonnella, J. S., Erdmann, J. B., et al. (2001). The jefferson scale of physician empathy: development and preliminary psychometric data. Educ. Psychol. Meas. 61, 349-365. doi: 10.1177/00131640121971158

Hojat, M., Mangione, S., Nasca, T. J., Gonnella, J. S., and Magee, M. (2005). Empathy scores in medical school and ratings of empathic behavior in residency training 3 years later. J. Soc. Psychol. 145, 663-672. doi: 10.3200/SOCP.145.6.663-672

Hojat, M., Mangione, S., Nasca, T. J., Rattner, S., Erdmann, J. B., Gonnella, J. S., et al. (2004). An empirical study of decline in empathy in medical school. Med. Educ. 38, 934-941. doi: 10.1111/j.1365-2929.2004.01911.x

Hojat, M., Vergare, M. J., Maxwell, K., Brainard, G., Herrine, S. K., Isenberg, G. A., et al. (2009). The devil is in the third year: a longitudinal study of erosion of empathy in medical school. Acad. Med. 84, 1182-1191. doi: 10.1097/ACM.0b013e3181b17e55

Jeon, S., and Cho, E. (2015). Assessment of korean pharmacy students' empathy using the jefferson scale of empathy. Am. J. Pharm. Educ. 79:67. doi: 10.5688/ajpe79567

Kay, J. (1990). Traumatic deidealization and the future of medicine. JAMA 263, 572-573. doi: 10.1001/jama.263.4.572

Kerr, J. L., Stahnke, A. M., and Behnen, E. M. (2015). Assessing empathy and selfefficacy levels of pharmacy students in an elective diabetes management course. Am. J. Pharm. Educ. 79, 42. doi: 10.5688/ajpe79342

Kohut, H. (1969). [Psychoanalytic therapy of narcissistic personality disorders]. Psyche (Stuttg) 23, 321-348.

Larson, E. B., and Yao, X. (2005). Clinical empathy as emotional labor in the patient-physician relationship. JAMA 293, 1100-1106. doi: 10.1001/jama.293.9.1100

Linley, P. A., and Joseph, S. (2007). Therapy work and therapists' positive and negative well-being. J. Soc. Clin. Psychol. 26, 385-403. doi: 10.1521/jscp.2007.26.3.385

Lor, K. B., Truong, J. T., Ip, E. J., and Barnett, M. J. (2015). A randomized prospective study on outcomes of an empathy intervention among second-year student pharmacists. Am. J. Pharm. Educ. 79:18. doi: 10.5688/ajpe79218

Maine, L., and Vogt, E. (2009). The courage to teach caring. Am. J. Pharm. Educ. 73:138. doi: 10.5688/aj7308138

Manolakis, M. L., Olin, J. L., Thornton, P. L., Dolder, C. R., and Hanrahan, C. (2011). A module on death and dying to develop empathy in student pharmacists. Am. J. Pharm. Educ. 75:71. doi: 10.5688/ajpe75471

Mehrabian, A., Young, A. L., and Sato, S. (1988). Emotional empathy and associated individual-differences. Curr. Psychol. Res. Rev. 7, 221-240. doi: 10.1007/Bf02686670

Neumann, M., Edelhauser, F., Tauschel, D., Fischer, M. R., Wirtz, M., Woopen, C., et al. (2011). Empathy decline and its reasons: a systematic review of studies with medical students and residents. Acad. Med. 86, 996-1009. doi: 10.1097/ACM.0b013e318221e615

Nightingale, S. D., Yarnold, P. R., and Greenberg, M. S. (1991). Sympathy, empathy, and physician resource utilization. J. Gen. Intern. Med. 6, 420-423. doi: 10.1007/Bf02598163

Nunes, P., Williams, S., Sa, B., and Stevenson, K. (2011). A study of empathy decline in students from five health disciplines during their first year of training. Int. J. Med. Educ. 2, 12-17. doi: 10.5116/ijme.4d47.ddb0

Rizzolatti, G., Fabbri-Destro, M., and Cattaneo, L. (2009). Mirror neurons and their clinical relevance. Nat. Clin. Pract. Neurol. 5, 24-34. doi: 10.1038/ncpneuro0990

Shamay-Tsoory, S. G. (2011). The neural bases for empathy. Neuroscientist 17, 18-24. doi: 10.1177/1073858410379268

Shamay-Tsoory, S. G., Aharon-Peretz, J., and Perry, D. (2009). Two systems for empathy: a double dissociation between emotional and cognitive empathy in inferior frontal gyrus versus ventromedial prefrontal lesions. Brain 132, 617-627. doi: 10.1093/brain/awn279

Tsimtsiou, Z., Kerasidou, O., Efstathiou, N., Papaharitou, S., Hatzimouratidis, K., and Hatzichristou, D. (2007). Medical students' attitudes toward patientcentred care: a longitudinal survey. Med. Educ. 41, 146-153. doi: $10.1111 / j .1365-2929.2006 .02668 . x$

Van Overwalle, F., and Baetens, K. (2009). Understanding others' actions and goals by mirror and mentalizing systems: a meta-analysis. Neuroimage 48, 564-584. doi: 10.1016/j.neuroimage.2009.06.009

Van Winkle, L., Dobie, S., Ross, V., Sharma, U., Green, J., and Lynch, S. (2009). Acute Intervention To Foster Reflection On Reciprocity In Relationships Increased Participants' Patient- Or Student-Centered Orientation Scores In Association With A Medical Biochemistry Course. Internet J. Med. Educ. 1:8.

Van Winkle, L. J., Bjork, B. C., Chandar, N., Cornell, S., Fjortoft, N., Green, J. M., et al. (2012a). Interprofessional workshop to improve mutual understanding 
between pharmacy and medical students. Am. J. Pharm. Educ. 76:150. doi: 10.5688/ajpe768150

Van Winkle, L. J., Cornell, S., Fjortoft, N., Bjork, B. C., Chandar, N., Green, J. M., et al. (2013a). Critical thinking and reflection exercises in a biochemistry course to improve prospective health professions students' attitudes toward physicianpharmacist collaboration. Am. J. Pharm. Educ. 77:169. doi: 10.5688/ajpe 778169

Van Winkle, L. J., Fjortoft, N., and Hojat, M. (2012b). Impact of a workshop about aging on the empathy scores of pharmacy and medical students. Am. J. Pharm. Educ. 76:9. doi: 10.5688/ajpe7619

Van Winkle, L. J., La Salle, S., Richardson, L., Bjork, B., Burdick, P., Chandar, N., et al. (2013b). Challenging medical students to confront their biases: a case study simulation approach. Med. Sci. Educ. 23, 217-224. doi: 10.1007/BF033 41624

Vogt, E. M., and Finley, P. R. (2009). Heart of Pharmacy: a course exploring the psychosocial issues of patient care. Am. J. Pharm. Educ. 73:149. doi: 10.5688/aj7308149

Williams, B., Brown, T., McKenna, L., Boyle, M. J., Palermo, C., Nestel, D., et al. (2014). Empathy levels among health professional students: a cross-sectional study at two universities in Australia. Adv. Med. Educ. Pract. 5, 107-113. doi: 10.2147/AMEP.S57569
Wilson, S. E., Prescott, J., and Becket, G. (2012). Empathy levels in first- and thirdyear students in health and non-health disciplines. Am. J. Pharm. Educ. 76:24. doi: 10.5688 /ajpe76224

Wolf, T. M., Balson, P. M., Faucett, J. M., and Randall, H. M. (1989). A retrospective study of attitude change during medical education. Med. Educ. 23, 19-23. doi: 10.1111/j.1365-2923.1989.tb00807.x

Conflict of Interest Statement: The authors declare that the research was conducted in the absence of any commercial or financial relationships that could be construed as a potential conflict of interest.

The reviewer AM declared a shared affiliation, though no other collaboration, with the authors to the handling Editor, who ensured that the process nevertheless met the standards of a fair and objective review.

Copyright (C) 2016 Tamayo, Rizkalla and Henderson. This is an open-access article distributed under the terms of the Creative Commons Attribution License (CC BY). The use, distribution or reproduction in other forums is permitted, provided the original author(s) or licensor are credited and that the original publication in this journal is cited, in accordance with accepted academic practice. No use, distribution or reproduction is permitted which does not comply with these terms. 